\title{
PENGARUH MODEL PEMBELAJARAN BERSIKLUS (LEARNING CYCLE $5 E)$ TERHADAP KEMAMPUAN BERPIKIR KRITIS SISWA
}

\author{
Meliana Rambu Kuba ${ }^{1}$ Agus Maramba Meha, ${ }^{2}$ Jusuf Blegur, ${ }^{3}$ \\ ${ }^{2}$ Universitas Kristen artha Wacana, Jl. Adi sucipto No. 147, Oesapa, Kec. Kelalpa Lima, Kota \\ Kupang, Nusa Tenggara Timur, 85228, Indonesia.
}

*Corresponding Author. E - mail: ${ }^{1}$ melianarambukuba@gmail.com

\begin{abstract}
Penelitian ini bertujuan untuk mengetahui pengaruh model pembelajaran bersiklus Learning Cycle $5 E$ terhadap kemampuan berpikir kritis pada siswa kelas VII SMPN 9 Kupang Timur tahun ajaran 20192020. Penelitian ini juga bertujuan untuk mengetahui tingkat signifikansi dari kedua metode dalam meningkatkan kemampuan berpikir kritis Salah upaya untuk mengatasi hal tersebut adalah dengan menerapkan model pembelajaran learning cycle 5 El 1 Engagement, Exsploration, Eksplanation, Elaboration, Evaluation.jenis Penelitian ini merupakan penelitian eksperimen semu (quasi eksperiment) dengan desain posttest-only cotrol group desain. Populasi penelitian ini adalah seluruh kelas VII dan sampelnya kelas VII ${ }^{A}$ dan VII ${ }^{B}$ dimana kelas VII ${ }^{A}$ sebagai kelas eksperimen kelas VII ${ }^{B}$ sebagai kelas kontrol. Instrumen yang digunakan dalam penelitian ini adalah tes esay kemampuan berpikir kritis. Uji normalitas menggunakan Kolmogorov Smirnov dan uji homogenitas menggunakan uji of homogenaity of variances. Berdasarkanhasiluji-t mengunakan Independt Sample Testdengan bantuan menggunakan SPSS versi 25. Diperoleh nilai signifikan 0,000 atau kurang dari 0 ,05 menunjukan bahwa terdapat pengaruh model Larning Cycle 5E tehadap kemampuan berpikir kriti s siswa.
\end{abstract}

\begin{abstract}
The aim of this study was to determine the effect of the $5 E$ Learning Cycle model on critical thinking skills in Grade VII students of SMPN 9 East Kupang in the academic year 2019/2020. This study also aims to determine the level of significance of the two methods in improving critical thinking skills. One of the efforts to overcome this is by implementing the 5 E learning cycle (1 Engagement, Exploration, Exploration, Elaboration, Evaluation) learning model. This research is used quasi-experimental with a posttest-only control group design.The population is class VII, and the sample consist of class VIIA that the experimental class, and class VIIB is the control class. The instrument used was an essay test of critical thinking skills. The normality test used the Kolmogorov Smirnov test, and the homogeneity test used the homogeneity of variances test. Based on the t-test results using the Independent Sample Test with the assistance of SPSS version 25, there is a significant value of 0.000 or less than 0.05. , this shows that there is an influence on students' critical thinking.
\end{abstract}

Keywords: 5E Learning Cycle Learning Model, Critical Thinking 



\section{Pendahuluan}

MenurutKomalasari (2013:3) berpendapat bahwa proses pembelajaran merupakan proses atau aktivitas yang direncanakan,dilaksanakan,dan dievaluasi secara sistematis agar pembelajaran dapat pencapai tujuan-tujuan pembelajaran secara efekrif dan efisien selanjutnya. Oleh sebab itu ke dua hal tersebut, baik belajar maupun mengajar mempunyai keterlibatan dalam menunjang hasil belajar siswa berdasarkn hasl obsevasi di sekolah guru belum maksiml mengembangakn pembelajaran berbasis kebutuhan siswa misalnya guru masi menggunakan cara lama yaitu model konvensional dalam menyampaikan materi kepada peserta didik .oleh sebab itu guru harus mampu mengelolah model pembelajaran yang tepat untuk mendukung proses pembelajaran. Salah satu model pembelajaran yang mendukung kemampuan berpikir kritis adalah model model pembelajaran Learning Cycle 5E.Model ini memberikan kesempatan kepada siswa untuk mengoptimalkan daya nalar atau kemampuan berpikir mereka melalui tahap-tahap kegiatan yang terdiri .1.Engagement membangkitkan minat siswa pada mata pelajaran,2.Exsploration memberikan kesempatan siswa untuk untuk untuk berinteraksi dalam bentuk kelompok,3.Explanation memberikan kesempatan kepada siswa untuk meyampaikan ide atau gagasa yang meraka miliki melalui kegiatan diskusi 4 . Elaborasi mengajak siswa mengaplikasikan konsep-konsep yang meraka dapat untuk memecahka masalah suatu permasalahan 5.Evaluasi mengevaluasi pengetahuan, pemahaman konsep atau kompetensi siswa. jadi model pembelajaran Learning Cycle $5 E$ adalah model yang menutut siswa berperan aktif dalam proses pembelajaran terkususnya dalam mengukur kemampuan berpikir kritis siswa.Menurut Aryulina (2009),penerapan model pembelajaran siklus belajarLearning Cycle 5Eyang terdiri atas tahap pelibatan, tahap penyelidikan/eksplorasi, tahap penjelasan/ pengenalan konsep, tahap penggalian, dan tahap penilaian dapat meningkatkan keterampilan inkuiri dan pemahaman konsep.

Kemampuan berpikir kritis adalah proses mental untuk menganalisis atau mengevaluasi informasi untuk memahami secara mendalam dan dapat membentuk sebuah keyakinaan kebenaran informasi dan pengambilan keputusan yang terbaik. Menurut Ennis (Fisher, 2011), berpikir kritis ialah pemikiran yang masuk akal dan reflektif yang berfokus untuk memutuskan apa yang mesti dipercaya atau dilakukan. Adapun aspek keterampilan berpikir kritis terdiri dari memberikan penjelasan sederhana, membangun keterampilan dasar, menyimpulkan, membuat penjelasan lanjut, serta strategi dan taktik yang terdiri dari sejumlah sub aspek dan indikator (Costa, 1985).

Berdasarkan kenyataan setelah melakukan observasi yang terjadi di sekolah, guru belum maksimal mengembangkan pembelajaran yang berbasis pada kebutuhan belajar siswa, Misalnya guru masih menggunakan cara yang lama yaitu metode ceramah dalam menyampaikan materi kepada peserta didik. Tentu hal ini sudah tidak sesuai dengan tuntutan kurikulum dan kebutuhan pengembangan diri siswa,metode ini juga menyebabkan rendahnya respon dan atau umpan balik dari siswa terhadap pertanyaan dan penjelasan guru. Selain itu, pemusatan perhatian juga menjadi terbatas, serta siswa cenderung tidak berpartisipasi aktif dalam meningkatkan dan mengembangkan kemampuan berpikir dan kepribadiannya. Apabila pola ini terus diterapkan maka kemampuan berpikir dan atau siswa tidak akan tercapai dan berkembang dengan baik

\section{Metode}

Penelitian di laksanakan di SMP N 9 Kupang Timur di Kelurahan Merdeka Kecamatan Kupang Timur Kabupaten 
Kupang. Penelitian dilakukan dengan mengunakan metode eksperimen semu (quasi exsperiment).. Desaian penelitian yang akan di gunakan pada penelitian ini adalah (posttest-only cotrol group desain) Posttest-Only Control Design kemampuan berpikir kritis siswa

\begin{tabular}{|l|l|l|}
\hline Kelas & Perlakuan & Posttest \\
\hline A & X & O1 \\
\hline B & - & O2 \\
\hline
\end{tabular}

Keterangan:

A/ B : kelas eksperimen / kelas kotrol $\mathrm{R}$ : Kelompok dipilih secara random $\mathrm{X}$ : Perlakuan model learning cycle $5 E$ O1 : Hasil postest kemampuan berpikir kritis siswa kelas eksperimen

O2: Hasil postest emampuan berpikir kritis siswa kelas kotrol.

- $\quad$ : Metode ceramah

Variabel yang dapat digunakan dalam penelitian ini adalah terbagi atas dua

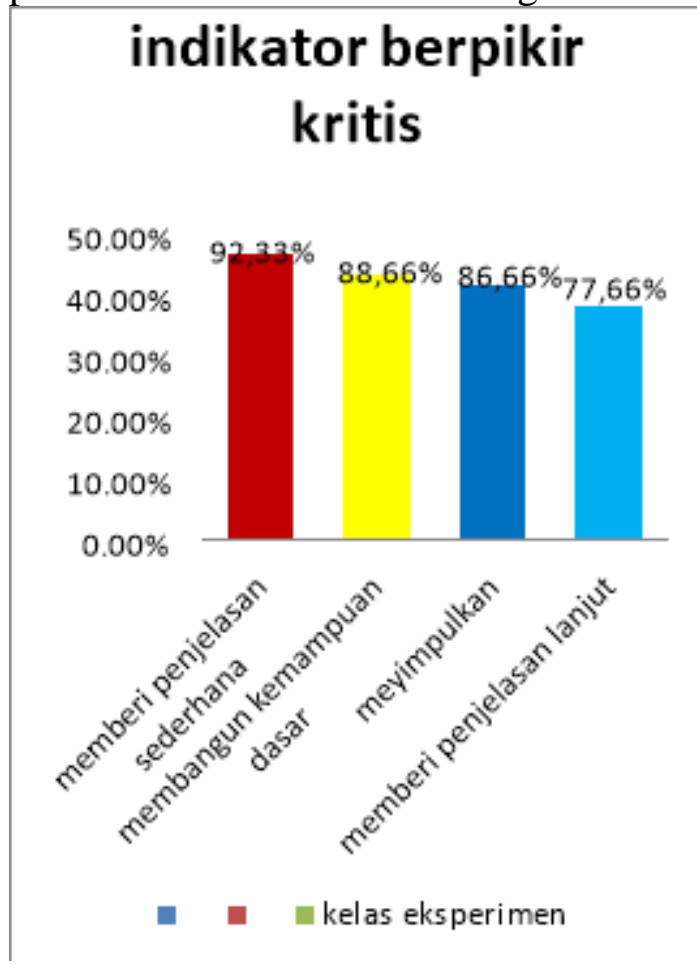

Berdasarkan Gambar 1 menunjukkanDi lihat dari indikator kemampuan berpikir kritis memberikan penjelasan sederhana memiliki presentase $92,33 \%$ sedangakan pada kelas kotrol $90,66, \%$ tidak jauh variabel yaitu variabel bebas dan variabel terikat.di mana varibel bebas model Learning Cycle 5edan terikat yaitu kemampuan berpikir kritis .pupulasi seluruh siswa kelas VII sebanyak 128 dan sampel yaitu kelas A dan kelas B sebanyak 56 orang. Teknik pengumpulan data yaitu menggunakan tes esay. Teknik analisis data dilakukan uji t- dengan bantuan komputer program SPSS versi 25

\section{Hasil Dan Pembahasan}

1. Deskripsi indikator berpikir kritis kelas eksperimen dan kelas kotrol

Hasil belajar Kemampuan berpikir kritis siswa terdapat Perbedaan pada indikator kemampuan berpikir kritis juga terlihat antara kelas eksperimen yang menggunakan model Learning Cycle 5E dan kelas control yang menggunakan metode konvensional (Gambar 1)

\section{indikator berpikir kritis}

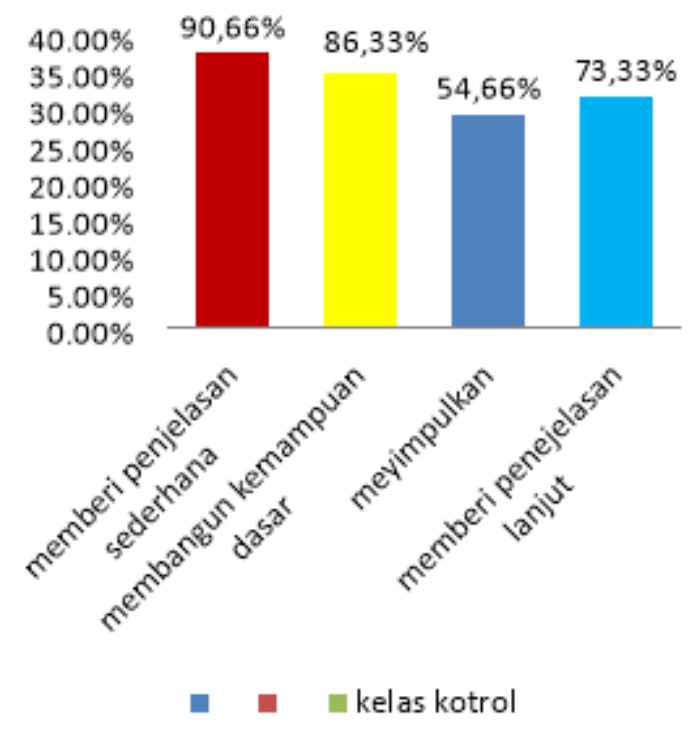

bedah dengan kelas kotrol di karenakan Selama kegiatan pembelajaran siswa mampu membuat suatu jawaban sederhana dari suatu permasalahan yang diberikan. Seperti siswa mampu 
menjelaskan seperti pengertian energi. Sesuai pernyataan Surya (2013:169) bahwa berpikir kritis memungkinkan seseorang untuk menganalisis, menilai, menjelaskan, dan merestrukturisasi pemikirannya. Selanjutnya siswa mengajukan pertanyaan kepada guru mengenai materi yang belum dipahami dan juga mengajukan pertanyaan pada kelompok.sedangakan pada Pada indikator membangun kemampuan dasar dengan presentasi $88.66 \%$ dan kelas kotrol $86,33 \%$, memiliki persentase tidak jauh bedah karena siswa lebih mudah menjelaskankonsepdibandingmempertim bangkankredibilitas.Dimana pada lembar LKS terdapat serangkaian pertanyaan yang membantu siswa untuk melatih proses berpikirnya baikdalammenjelaskankonsepsertadapatm enyelidikiinformasidanpengalamantertent entu.

Pada indikator menyimpulkan memiliki presentasi $86,66 \%$ dan pada kelas kotrol $54,66 \%$ hal ini disebabkan oleh pelaksanan pembelajaran dikelas control yang cendrung dikuasai guru dimana yang lebih dominan adalah metode ceramah, hal ini berbeda pada kelas eksperimen kemampuan siswa dalam aspek meyimpulkan sudah cukup baik dimana mendapatkan dalam proses pembelajaran menggunakan model Learning Cycle 5Esiswa dilibakan secara aktif dalam pembelajaran, siswa dituntut untuk berkerja sama dengan temannya. Menurut Susanto (2012: 129-128) salah satu tahapan untuk mengajarkan atau melatih siswa agar mampu berpikir kritis adalah keterampilan menyimpulkan, pembaca dituntut untuk mampu menguraikan dan memahami berbagai aspek secara bertahap agar sampai kepada suatu formula baru yaitu sebuah simpulan. Sedangkan indikator yang terakhir yaitu memberi penjelasan lebih lanjut dengan presentasi pada kelas eksperimen $77,66 \%$ dan kelas kotrol 73,33\% terdiri atas siswa mengidentifikasi istilah-istilah dan definisi pertimbangan dan juga dimensi, serta mengidentifikasi asumsi

Ujiprasyaratdilakukansebelummela kukanujihipotesi, dengan menggunakan uji homogenitas dan normalitas. Berdasarkan uji homogenitas menunjukkan nilai signifikan sebesar 0,134 lebih besar dari 0,05. Artinya bahwa data penelitian homogen. Selanjutnya berdasarkan uji normalitas menunjukkan nilai Asymp. Sig. (2-tailed) sebesar 0.236 lebih besar dari nilai alfa 0,05 . Artinya data berdistribusi normal.selanjutnya dilakukan pengujian hipotesis bertujuan untuk melihat ada tidaknya pengaruh penggunaan model pembelajaran Learning Cycle $5 E$ terhadap kemampuan berpikir kritis siswa 


\section{Tabel 1. Hasil analisis uji t kemampuan berpikirkritis}

\begin{tabular}{|c|c|c|c|c|c|c|c|c|c|c|}
\hline \multicolumn{11}{|c|}{ Independent Samples Test } \\
\hline & & \multicolumn{2}{|c|}{\begin{tabular}{|l|}
\multicolumn{2}{|l|}{ Levene's } \\
Test for \\
Equality of \\
Variances \\
\end{tabular}} & \multicolumn{7}{|c|}{ t-test for Equality of Means } \\
\hline & & \multirow[b]{2}{*}{$\mathrm{F}$} & \multirow[b]{2}{*}{ Sig. } & \multirow[b]{2}{*}{$\mathrm{t}$} & \multirow[b]{2}{*}{ Df } & \multirow{2}{*}{$\begin{array}{l}\text { Sig. } \\
(2- \\
\text { tailed })\end{array}$} & \multirow{2}{*}{$\begin{array}{l}\text { Mean } \\
\text { Difference }\end{array}$} & \multirow{2}{*}{$\begin{array}{l}\text { Std. Error } \\
\text { Difference }\end{array}$} & \multicolumn{2}{|c|}{$\begin{array}{l}95 \% \text { Confidence } \\
\text { Interval of the } \\
\text { Difference }\end{array}$} \\
\hline & & & & & & & & & Lower & Upper \\
\hline \multirow[t]{2}{*}{ Berpikirkritis } & \begin{tabular}{|l} 
Equal \\
variances \\
assumed
\end{tabular} & 2.294 & .136 & 6.528 & 54 & .000 & 15.0115 & 2.2997 & 10.4010 & 19.6221 \\
\hline & $\begin{array}{l}\text { Equal } \\
\text { variances } \\
\text { not } \\
\text { assumed }\end{array}$ & & & 6.619 & 53.878 & .000 & 15.0115 & 2.2679 & 10.4645 & 19.5586 \\
\hline
\end{tabular}

Hasilperhitunganujiperbedaan ratarata yang dapatdilihatpadakolomt-test for Equality of Means.PadaEqual variances assumed diperolehnilai t sebesar6.528 dan tarafsignifikan $\mathrm{p}=0,000$ atau kurangdari 0,05. Artinya bahwa penggu-naan model pembelajaran Learning Cycle 5ETerhadap kemampuan berpikir kritis siswa.

Berdasarkan hasil sebelumya diketahui kemampuan berpikir kritis terdapat pada kelas eksperimen, hal ini disebabkan karena model pembelajaran Learning Cycel $5 E$ diterapkan pada kelas eksperimen dapat meningkatkan kemampuan berpikir kritis. Dalam pelaksanaan pembelajaran. Model pembelajaran Learning Cycel $5 E$ yang menuntut keterlibatan secara optimal dalam proses belajar dapat meningkatkan kemampuan berpikir kritis. Hal ini sejalan dengan Verawati \& Harjono (2017) yang menyatakan bahwa model Learning Cycle $5 E$ adalah model yang di kembangkan untuk menciptakan aktivitas pembelajaran yang efektif dan efisien dalam meningkatkan kemampuan berpikir kritis dalam hal ini denganmengunakan model Learning Cycle 5E,terdapat padalangkalangka "pembangkit minat (enggament)'pa da tahap ini siswauntuksalingberinteraksidalammenjaw abpertanyaan yang di ajukan oleh guru yang berkaitan dengan topik pembahasan.Denganadanyainteraksiinime mbuatsiswalebihaktifdalammencariinform asiuntukmenjawabsetiappertanyaan.menur ut Wena (2012 ) hal yang di lakukan dengan cara mengajukan pertayaan tentang proses faktual dalam kehidupan sehari-hari yang berhungan dengan topik.

Pada bagian " peyelidikan (eksplorasi)dalam tahap ini siswa antusias mengerjakan soal-soal dalam bentuk kelompok masing-masing sesui soal yang diberikan dan diberikan kesempatan untuk berkerjasama untuk menguji hipotesis baru dan guru sebagai fasilitator saja dan siswa begitu antusias dalam bekerja kelompok akan tetapi tidak terlepas dari kendala yang dihadapi pada saat proses pembelajaran kurang maksimal menjalankan langkah-langkah kedua dari model Learning Cycle 5E karena pneitikurangmemahamidanmengertimaksu ddarisintax model pembelajaranLearning Cycle $5 E$ bagian langka kedua karena pada langka tersebut seharunya siswa diminta untuk melakukan penyelidikan suatu kasus dalam proses diskusi tapi soal LKS yang diberikan oleh guru tidak sesuai dengan prosedur langkah kedua. Tetapi tidak menjadi penghambat terhadap nilai atau keaktifan siswa dalam proses pembelajaran karena sintax yang lain dijalankan sesuai langka-langka yang ada. 
Pada bagian " peyelidikan (eksplorasi)dalam tahap ini siswa antusias mengerjakan soal-soal dalam bentuk kelompok masing-masing sesui soal yang diberikan dan diberikan kesempatan untuk berkerjasama untuk menguji hipotesis baru dan guru sebagai fasilitator saja dan siswa begitu antusias dalam bekerja kelompok akan tetapi tidak terlepas dari kendala yang dihadapi pada saat proses pembelajaran kurang maksimal menjalankan langkah-langkah kedua dari model Learning Cycle 5E karena peneiti kurang memahami dan mengerti maksud dari sintax model pembelajaran Learning Cycle $5 E$ bagian langka kedua karena pada langka tersebut seharunya siswa diminta untuk melakukan penyelidikan suatu kasus dalam proses diskusi tapi soal LKS yang diberikan oleh guru tidak sesuai dengan prosedur langkah kedua. Tetapi tidak menjadi penghambat terhadap nilai atau keaktifan siswa dalam proses pembelajaran karena sintax yang lain dijalankan sesuai langka-langka yang ada. Pada bagian tahap penjelasan (explanation) siswa menjelaskan hasil diskusi kelompok didepan kelas dan siswa lain menanggapi dan mengkritisi hasil diskusi penyaji dan menjawab pertanyaan dari siswa lain dan menjelaskan konsep yang akan dipelajari hal ini akan memicu kemampuan siswa dalam mencari informasi dan merasa bertanggungjawab atas pertayaan-pertayaan yang diberikan oleh guru, sehinggapa dan proses pembelajaran guru hnya sebagai fasilitator saja dalam tahap ini karena dalam model pembelajaran ini siswa yang berperan aktif.

\section{Simpulan}

Berdasarkan hasil penelitian maka dapat disimpulkanbahwa ada pengaruh yang signifikan pada penggunaan model pembelajaran Learning Cycle 5E terhad apkemampuanberpikirkritis siswa di SMP Negeri 9 Kupang Timur Tahun Ajaran 2019/2020.Hal ini dibuktikan dengan hasil uji hipotesis menggunakan rumus uji $\mathrm{t}$ dimana hasil analisis data pada perhitungan Independent Samples Test menunjukan nilai signifikan Equal variances assumed mempunyai taraf signifikan Sig. (2-tailed) $=0.000$ yang artinya $<0,05$. Berarti ha di terima dan Ho di tolak. Hal tersebut menunjukan bahwa terdapat pengaruh yang signifikan terhadap kemampuan berpikir kritis siswa pada kelas eksperimen berarti adanya perbedaan kemampuanberpikirkritis antara kelas eksperimen dan kelas kontrol.

\section{Daftar pustaka}

Aryulina, D. (2009). Implementation of $5 \mathrm{E}$ Learning Cycle to Increase Students' Inquiry Skills and Biology Understanding. Jurnal Kependidikan Triadik, 12(1). 45-55.

Costa, A. L. 1985. Developing Minds: A Resource Book for Teaching Thinking. Alexandria, Va: Association for Supervision and Curriculum Development.

Darusman, B. (2015). Persepsi Mahasiswa terhadap Kontribusi HMP PGSD dalam Mengoptimalkan Kemampuan Berpikir Kritis Mahasiswa PGSD FKIP Universitas Muhammadiyah Surakarta. Skripsi, Universitas Muhammadiyah Surakarta.

Ennis R. H. (2011). The Nature of Critical Thinking: An Outline of Critical Thinking Dispositions and Abilities. University of Illinois

Facione, P. A.. 2011. Critical Thinking: What It Is and Why It Counts. Millbrae, CA Measured Reasons and The California Academic Press.

Fajaroh, F . \& Dasna, I. W. 2007. ModelModel Pembelajaran Inovatif. Malang: Universitas Negeri Malang. 
Fisher, A. 2011. Critical Thinking: An Introduction. Cambridge: Cambridge University Press.

Gunawan, G., \& Liliasari, L. (2012). Model Virtual Laboratory Fisika Modern untuk Meningkatkan Disposisi Berpikir Kritis Calon Guru. Jurnal Cakrawala Pendidikan, 5(2), 185-199. DOI:https://doi.org/10.21831/cp.v5i 2.1556

Penulis pertama yaitu Meliana Rambu Kuba di Lahirkan di Lawonda, desa Mata Waikajawi Kecamatan Umbu Ratu Nggay Barat Kabupaten Sumba Tengah. pada tanggal 25 Mei 1996. Merupakan anak kedua dari Pasangan Suami Isti Bapak Mema Umbu Sakalla dan Ibu Rambu Wasak Lodang. Penulis memulai pendiikan dari SDM (Sekolah Dasar Masehi) Lawonda pada tahun 2003 dan tamat pada tahun 2009, di tahun yang sama penulis melanjutkan studi di jenjang sekolah menengah pertama yaitu Sekolah Menengah Pertama Negeri 1 Umbu Ratu
Nggay Barat dan tamat di tahun 2012. Pada tahun 2012 melanjutkan studi di Sekolah Menengah Kejuruan Negeri 1 Waibakul dan tamat pada tahun 2015. Pada tahun 2015 penulis melanjutkan studi di perguruan tinggi Universitas Kriten Artha Wacana Kupang dan diterima di Fakultas Keguruan dan Ilmu Pendidikan Program Studi Biologi

Penulis keduayaituAgus Maramba Meha,S.Pd,M,Pd merupakan dosen Universitas Kristn Artha Wacana Kupang Program Studi Pendidikan Biologi

Penulis ketiga yaitu Jusuf Blegur S.Pd,M,Pd merupakan dosen di Universitas Kristn Artha Wacana Kupang Program Studi Pendidikan PJOK. 